\title{
O comportamento do consumidor e a sua decisão no ato de compra - uma revisão de
}

\section{literatura}

\author{
Consumer behavior and your decision in the act of purchase - a literature review \\ Comportamiento del consumidor y su decisión en el acto de compra - una revisión de la literatura
}

Recebido: 2710/2021 | Revisado: 06/11/2021 | Aceito: 09/11/2021 | Publicado: 14/11/2021

Cátia Oliveira Silva

ORCID: https://orcid.org/0000-0001-7275-896X Faculdades Integradas Aparício Carvalho, Brasil

E-mail: catiaoliveira22051996@gmail.com

Francisco Sérgio Pereira Silva

ORCID: https://orcid.org/0000-0002-3541-5332

Faculdades Integradas Aparício Carvalho, Brasil

E-mail: franckpsilva17@gmail.com

Renato Nascimento Silva Anastácio

ORCID: https://orcid.org/0000-0002-5285-664X

Faculdades Integradas Aparício Carvalho, Brasil

E-mail: renatonascimento1996.rs@ gmail.com

Denilson Nunes Moreira

ORCID: https://orcid.org/0000-0002-5997-9263

Faculdades Integradas Aparício Carvalho, Brasil

E-mail: prof.denilsonpvh@gmail.com

\begin{abstract}
Resumo
$\mathrm{O}$ atual processo de globalização acelerou pari passu o movimento de pessoas e do processo de consumo, rompendo linhas sociais e geográficas habituais. A ascensão da tecnologia está concebendo uma nova economia, em detrimento as velhas práticas econômicas aplicadas, obrigando as pessoas a mudarem suas maneiras de se comportarem como consumidores. Amoldando um novo momento em sentido de dimensão, rapidez, fluxo e direção, A história contemporânea mundial regista uma transformação econômica da riqueza em andamento sem paralelos. Tal mudança nós já prevíamos, mas sua chegada acabou nos impactando, e em seu rastro há mais imprevistos do que certezas, e quem sente tudo isso de perto é a população em torno do mundo. Na composição desse cenário é imprescindível mencionar os embaraços provocados pela pandemia causada pelo novo coronavírus, que acrescentou ainda mais instabilidade nas bases econômicas e estruturais mundial. De outa forma, gradualmente, as pessoas almejam por uma qualidade mais razoável de vida e conseguinte de consumo. Tudo isso paira sobre o comportamento do consumidor, que é o objeto eixo da nossa abordagem. Sendo assim, esse artigo tem como objetivo identificar o comportamento do consumidor no ato de comprar. Através do registro dos fatores motivacionais, das fontes condicionantes as atitudes e das fases que compõem o processo decisório do consumidor, adotando o método de pesquisa bibliográfica, optando por autores com proposições no segmento, do que há de mais meritório e de referência atualmente no meio teórico sobre o referido tema.
\end{abstract}

Palavras-chave: Influência; Comportamento; Consumidor; Decisão de compra.

\begin{abstract}
The current globalization process has accelerated pari passu the movement of people and the consumption process, breaking the usual social and geographic lines. The rise of technology is designing a new economy, to the detriment of old applied economic practices, forcing people to change their ways of behaving like consumers. Shaping a new moment in terms of dimension, speed, flow, and direction, Contemporary world history records an unparalleled economic transformation of wealth in progress. We had already foreseen this change, but its arrival ended up impacting us, and in its wake, there are more unforeseen events than certainties, and people around the world feel all this up close. In the composition of this scenario, it is essential to mention the embarrassments caused by the pandemic caused by the new coronavirus, which added even more instability to the world's economic and structural bases. On the other hand, gradually, people aim for a more reasonable quality of life and consequent consumption. All this hangs over consumer behavior, which is the central object of our approach. Therefore, this article aims to identify consumer behavior in the act of shopping. Through the registration of motivational factors, the conditioning sources, attitudes and phases that make up the decision-making process of the consumer, adopting the bibliographic research method, opting for authors with propositions in the segment, what is most meritorious and of reference currently in the environment theoretical on the subject.
\end{abstract}

Keywords: Influence; Behavior; Consumer; Purchase decision. 


\section{Resumen}

El actual proceso de globalización ha acelerado pari passu el movimiento de personas y el proceso de consumo, rompiendo las habituales líneas sociales y geográficas. El auge de la tecnología está diseñando una nueva economía, en detrimento de las viejas prácticas económicas aplicadas, lo que obliga a las personas a cambiar su forma de comportarse como consumidores. Dando forma a un nuevo momento en términos de dimensión, velocidad, flujo y dirección, la historia mundial contemporánea registra una transformación económica sin precedentes de la riqueza en curso. Ya habíamos previsto este cambio, pero su llegada nos acabó impactando, y a su paso hay más imprevistos que certezas, y la gente de todo el mundo lo siente de cerca. En la composición de este escenario, es fundamental mencionar los embates provocados por la pandemia provocada por el nuevo coronavirus, que ha sumado aún más inestabilidad a las bases económicas y estructurales del mundo. Por otro lado, gradualmente, las personas buscan una calidad de vida más razonable y el consiguiente consumo. Todo esto pende sobre el comportamiento del consumidor, que es el objeto central de nuestro enfoque. Por tanto, este artículo tiene como objetivo identificar el comportamiento del consumidor en el acto de compra. Mediante el registro de factores motivacionales, las fuentes condicionantes, actitudes y fases que configuran el proceso de toma de decisiones del consumidor, adoptando el método de investigación bibliográfica, optando por autores con propuestas en el segmento, lo más meritorio y de referencia actualmente en el entorno teórico sobre el tema. Palabras clave: Influencia; Comportamiento; Consumidor; Decisión de compra.

\section{Introdução}

Na contemporaneidade os consumidores procuram satisfazer suas necessidades, pois suas exigências têm sido cada vez maiores, em busca da qualidade, seja em um produto ou serviço. Entretanto, algumas empresas falham, não pela falta da qualidade do produto, mas por apresentar na maioria das vezes um atendimento insatisfatório ou quando se tem um atendimento plausível, o produto deixa a desejar quanto à qualidade. Em caso de um serviço, por exemplo, uma empresa de internet pode atender bem, no entanto, o seu serviço é ruim ou vice e versa. Para que se tenham consumidores mais satisfeitos é necessário que se tenha uma excelente qualidade do produto aditada ao atendimento.

Entender a necessidade do consumidor não é tarefa fácil, pois abrange vários pontos como financeiro, emocional e localidade, para isso a necessidade de existir profissionais capacitados para atender este público é fundamental, onde não somente o colaborador, mas também a empresa precisa estar atenta a cada detalhe novo que será inserido neste contexto (Gomes, 2020).

Para Limeira (2008), as decisões de marketing que se baseiam em premissas teóricas e em pesquisas têm maior probabilidade de serem bem-sucedidas, em detrimento as que se baseiam apenas em palpites ou intuição. Nesse sentido, o conhecimento acerca do comportamento do consumidor pode ser uma importante vantagem competitiva, pois é possível que reduza muito a probabilidade de se tomar decisões ruins e de falhas na comercialização.

O presente artigo trata-se de uma revisão de literatura do tipo narrativa, com natureza básica, sua abordagem é qualitativa. Tem como objetivo principal identificar o comportamento do consumidor no ato de comprar. Por meio do registro dos fatores motivacionais, das fontes condicionantes as atitudes e das fases que compõem o processo decisório do consumidor. Nele será apresentado os elementos mais significativos que impulsionam os compradores, os motivos desconhecidos por trás de suas escolhas, como acontece a formação de suas atitudes e os estágios que vão desde o reconhecimento das necessidades até o pós-consumo. Dessa forma o mesmo buscará responder a seguinte pergunta: Qual o comportamento do consumidor e a sua decisão no ato de comprar.

\section{Metodologia}

O estudo consistiu em uma pesquisa de natureza bibliográfica do tipo narrativa, que segundo (Casarin et al.,2020) estabelece uma forma importante de revisar a literatura para buscar atualizações a respeito de um determinado assunto dando ao revisor suporte teórico útil na descrição do estado da arte de um assunto específico, sob o ponto de vista teórico ou contextual. De acordo com Gil (2002), a pesquisa bibliográfica é executada através de livros, artigos científicos, dissertações, teses e outros. Quanto aos objetivos desta pesquisa é classificada como descritiva, pois analisa, registra, observa e correlaciona fatos ou fenômenos sem manipulá-los. Com muita precisão descobre a periodicidade que os fatos ocorrem na vida social, econômica e 
aspectos relacionados ao comportamento humano, buscando apontar a ligação e a vinculação que os mesmos têm há outros elementos (Lakatos \& Marconi como citado em Oliveira, 2011).

A pesquisa foi realizada no período compreendido entre fevereiro de 2019 a outubro de 2021, empreendida por meio de busca eletrônica (via internet) através das plataformas Scientific Electronic Library Online (SciELO), Periódicos CAPES, Google acadêmicos e livros atinentes ao tema, considerando artigos condescendentes ao assunto, publicados entre o período de 2000 a 2021. Como critérios de inclusão foram selecionados os estudos disponíveis na íntegra e em língua portuguesa, que se aproximam da temática estudada, realizado nas seguintes categorias temáticas: comportamento do consumidor, fatores que influenciam o consumidor e consumo. Foram desconsiderados os artigos publicados em língua estrangeira, os de referência duvidosa, os sem relevância ou que não demostram relação direta com o tema.

\section{Resultados e Discussões}

\subsection{Consumo}

O consumo é o meio muito utilizado para suprir as reais necessidades no dia a dia das pessoas. Dessa forma ele é utilizado com a finalidade de satisfazer as devidas necessidades que vão surgindo ao longo da rotina dos indivíduos, sejam elas de comer, vestir, calçar, ter um lar para morar e etc. (Content, 2017). Antes da primeira revolução industrial só era possível consumir um produto ou serviço de seu interesse por meio de trocas, esse modelo é conhecido como feudalismo, posteriormente com o surgimento da primeira revolução industrial o sistema mudou de feudal para capitalista e com o aparecimento de novas fontes de renda as pessoas passaram adquirir produtos e serviços com mais facilidade (Sousa, 2021).

Nas palavras de Fernandes (2010) o cidadão consumidor foi o meio encontrado pelo capitalismo para que o contingente de produção fosse absorvido. Logo, este se tornou o elo entre o novo ciclo da produção e o ciclo do consumo.

Segundo Marques (2020), a economia brasileira nos últimos três anos permanece ancorada na demanda interna, principalmente no consumo das famílias, que em números, representa 65\% do PIB brasileiro.

Nesse sentido Kotler (2006), salienta que a empresa tem como obrigação ter uma estrutura orientada para o cliente, sendo o mesmo no topo da pirâmide hierárquica e sucedendo o pessoal da linha de frente, em seguida a gerência de nível médio e pôr fim a alta administração. De acordo com Silva (2012), principalmente no que diz respeito ao marketing, que se apresenta como uma função eficaz na comunicação e na relação da empresa com os consumidores.

A qualidade vai além das expressões deixadas pelo consumidor, ou seja, muitas vezes o desejo do consumidor é sutil, as empresas devem estar atentas sobre isso. Nesse contexto a empresa também visa uma melhor satisfação aos seus clientes colocando-os no topo de exigibilidade na empresa (Kotler, 2006).

No entendimento de Rossetti (2003) "Os consumidores buscam a maximização da satisfação de suas necessidades", todavia existem motivações que influenciam nas decisões dos consumidores na hora de comprar um produto sendo elas cognitivas, emocionais ou intencionais.

As pessoas recebem influências internas e externas, onde ambas definem o comportamento ao consumir. Sendo as influências internas os fatores psicológicos que são a motivação, o aprendizado, as atitudes e pôr fim a personalidade e as influências externas onde nestas se englobam a família, a classe social a qual esse indivíduo pertence, os grupos de referência e cultura (Las Casas, 2000). No estudo dos estímulos presentes na atmosfera de consumo, torna-se relevante considerarmos as influências. Tais evidências devem ser observadas e com esse propósito, elegemos em seguida, os fatores que desempenham notórias influências no comportamento do consumidor.

Para que possamos ampliar nossa compreensão sobre o assunto, apontamos como alguns dos principais teóricos do marketing definem o tema. 


\subsection{Fatores que influenciam os consumidores}

\subsubsection{Psicológicos}

Os fatores psicológicos têm um certo envolvimento no estudo, da percepção, aprendizagem, motivação, crenças, valores, e pôr fim do modo de vida de uma pessoa (Richardson, 2017).

A motivação está ligada à quando o indivíduo deseja ter algo, isto pode partir de dois pontos centrais: o impulso ou o hábito do dia a dia. O consumidor não pode controlar os acontecimentos, e tão menos aquilo que o influencia a efetuar a compra. O indivíduo possui necessidades que o motiva a comprar, estas necessidades podem ser de autorrealização, de estima, sociais, segurança e por fim as fisiológicas (Binotto et al.,2014).

\subsubsection{Fatores Pessoais}

Sendo considerada um dos fatores de maior motivação no processo decisório de compra, a personalidade de uma pessoa influencia grandemente nesse processo, pois está interligado com dificuldades pessoais de cada indivíduo e obstáculos emocionais, enfrentados pelo mesmo. Levando a motivar as funções cognitivas onde estas referem-se aos pensamentos e as funções afetivas relacionadas ao sentimento de cada indivíduo (Silva et al.,2021).

\subsubsection{Grupos de Referência}

A família normalmente tem maior influência sobre as decisões de consumo de um indivíduo, porque as pessoas baseiamse na confiança e na proximidade. Os grupos de amigos fazem parte dos grupos informais, pois os mesmos não possuem estrutura ou níveis específicos, contudo depois da família são os maiores influenciadores de consumo. As pessoas também formam grupos de compras, que nada mais é do que duas ou mais pessoas que decidem sair juntas para comprar alimentos ou roupas, normalmente esse tipo de grupo deriva da família e a sua tomada de decisão é coletiva. Os grupos de trabalho baseiam-se nas pessoas que trabalham juntas em uma mesma equipe, este grupo tem certa influência sobre o consumo de um indivíduo, isto ocorre devido ao convívio diário que uma pessoa tem com os demais de sua equipe. Por isso as pessoas passam a obter hábitos de consumo dos grupos em que elas pertencem (Franco et al., 2017).

No século XXI tem muitas pessoas que trabalham nas redes sociais influenciado a vida de muitos indivíduos, e seus hábitos de consumo, para Moura (2019), influenciadores digitais são capazes de induzir pessoas a um determinado nicho de mercado, usando habilidades de publicidade, pois conseguem trabalhar na escolha de consumo de uma nova geração.

\subsubsection{Fatores Sociais}

É por meio dos fatores sociais que acontece a interação social entre dois ou mais indivíduos, este também é considerado um ponto relevante no processo decisório do comprador, pois é que nele está contido os grupos de convívio aos quais o indivíduo pertence, levando em consideração a faixa etária dos mesmos, estes fatores modelam, induzem e mudam o comportamento do consumidor (Teixeira, 2010). Segundo Sachs e Larrain (2000), diz que na juventude as pessoas têm um hábito maior ao consumo contraindo assim várias dívidas, pois acreditam que ganharam bastante dinheiro posteriormente, após anos quando estes chegam a meia idade e quitam suas dívidas contraídas anteriormente e começam a poupar para sua velhice. O autor aborda que existe um pico de consumo na vida das pessoas podendo ser mais alto quando se está na mocidade. 


\subsubsection{Fatores Culturais}

A cultura pode ser definida como: os conhecimentos, as crenças, a arte, a moral, as leis, os costumes ou hábitos obtidos por uma pessoa adentro da sociedade. (Barros como citado em Tylor, 2014). Os fatores culturais são altamente determinantes na conduta e nas vontades de um indivíduo. No caso de uma criança quando ela cresce dentro de uma determinada cultura ela adquire certos valores, entendimento, escolha e o comportamento de sua família e de outras entidades (Kotler, 2000).

\subsection{Formação das Atitudes}

Para Cavazza (2008), as nossas atitudes e opiniões são interessantes para as agências de marketing, cuja as finalidades estão ligadas à possibilidade de agir sobre as atitudes e sobre as opiniões das pessoas, para orientá-las em proveito próprio e transformá-las em comportamentos que induzem à compra (Tabela 1).

Tabela 1 - Formação das atitudes.

\begin{tabular}{|l|l|}
\hline Emoção & $\begin{array}{l}\text { O consumidor não consegue resistir às compras, principalmente se seus produtos } \\
\text { favoritos estiverem em promoção ou até mesmo uma data de pagamento prolongada. }\end{array}$ \\
\hline Benefícios & Estes são classificados de acordo com o que o produto pode lhe proporcionar. \\
\hline Status & A posição social em que o consumidor se encontra, irá definir os produtos que ele vai utilizar. \\
\hline Utilidade & Refere-se ao grau de necessidade do consumidor, o quanto o produto é útil para o mesmo. \\
\hline Cognição & O consumidor compra porque já conhece o produto e sabe que ele é bom. \\
\hline
\end{tabular}

Fonte: Autores (2021).

Nas palavras de (Ugalde \& Slongo, 2006), as experiências cotidianas sugerem que, logo após ter-se uma emoção, há uma modificação corporal, seguindo a uma ordem sequencial de estímulo-emoção-reação fisiológica. Ainda segundo alguns autores a emoção também é vista como uma função biológica do sistema nervoso e como força que, juntamente com a razão, participa do processo decisório do consumidor (Sauerbronn, et al., 2009).

Atinente aos benefícios, o produto possui diversas características representa aquilo que é oferecido a mais que seu objetivo principal. Por isso, torna-se importante que esses benefícios sejam vistos pelo consumidor, pois estes são fatores considerados relevantes no momento da compra. Afinal, o motivo pelo qual o consumidor adquiri um produto é pelos benefícios que o mesmo proporciona, salienta (Werlang como citado em Las Casas 2006).

No que concerne ao status no ato de consumir, Castilhos (2007) comenta que na sociedade brasileira, alguns bens, serviços e práticas de consumo ainda podem ser associados a uma determinada posição social. Segundo Ribeiro (2010) um exemplo disso é o consumidor da classe média, com maior poder de compra, vai atrás de novas necessidades. Ele cria desejos de consumo que não tinha antes. Um reflexo disso é o aumento nas vendas dos produtos com maior nível de sofisticação.

No que está relacionado a ação de comprar devido a utilidade do bem Chrestenzen e Santos (2018), apontam que as escolhas do consumidor por uma determinada gama de produtos e serviços, estão inteiramente ligadas a utilidade que o bem ou serviço lhe proporciona.

“Os clientes não compram produtos apenas por suas características físicas, mas sim por seus benefícios ou utilidades. Isso significa que o negócio deve acompanhar o passo do consumidor para oferecer, por meio do produto/serviço, o conjunto de benefícios (funcionais e emocionais) que o satisfaça (Mota, 2021).” 
A composição da atitude é um resultado do aprendizado. A atitude pode ser demonstrada pelo condicionamento clássico onde os consumidores adquirem novos produtos com certa frequência, por marcas bem-conceituadas no mercado, portanto, isto se deriva de produtos que já foram consumidos da mesma marca ou empresa (Schiffman \& Kanuk, 2000).

A título de exemplo, se uma pessoa já conhece a marca e sabe que seus produtos são de excelente qualidade, quando a marca lançar novos produtos a mesma não perderá tempo e logo vai adquirir este produto sem qualquer receio, outro elemento é a teoria cognitiva da aprendizagem, sendo as bases de conhecimento ou crenças sendo elas positivas ou negativas pelos consumidores que têm sobre determinado produto.

\subsection{Fases do processo decisório do consumidor}

O processo de compra como o modo de compreensão do surgimento da necessidade de comprar por parte dos consumidores. Este processo passa por cinco fases (figura 1): reconhecimento da necessidade, busca de informação, avaliação de alternativas, escolha (compra), e análise pós-compra (Dias como citado em Ambros, 2019).

Figura 1 - Fases do processo de compra.

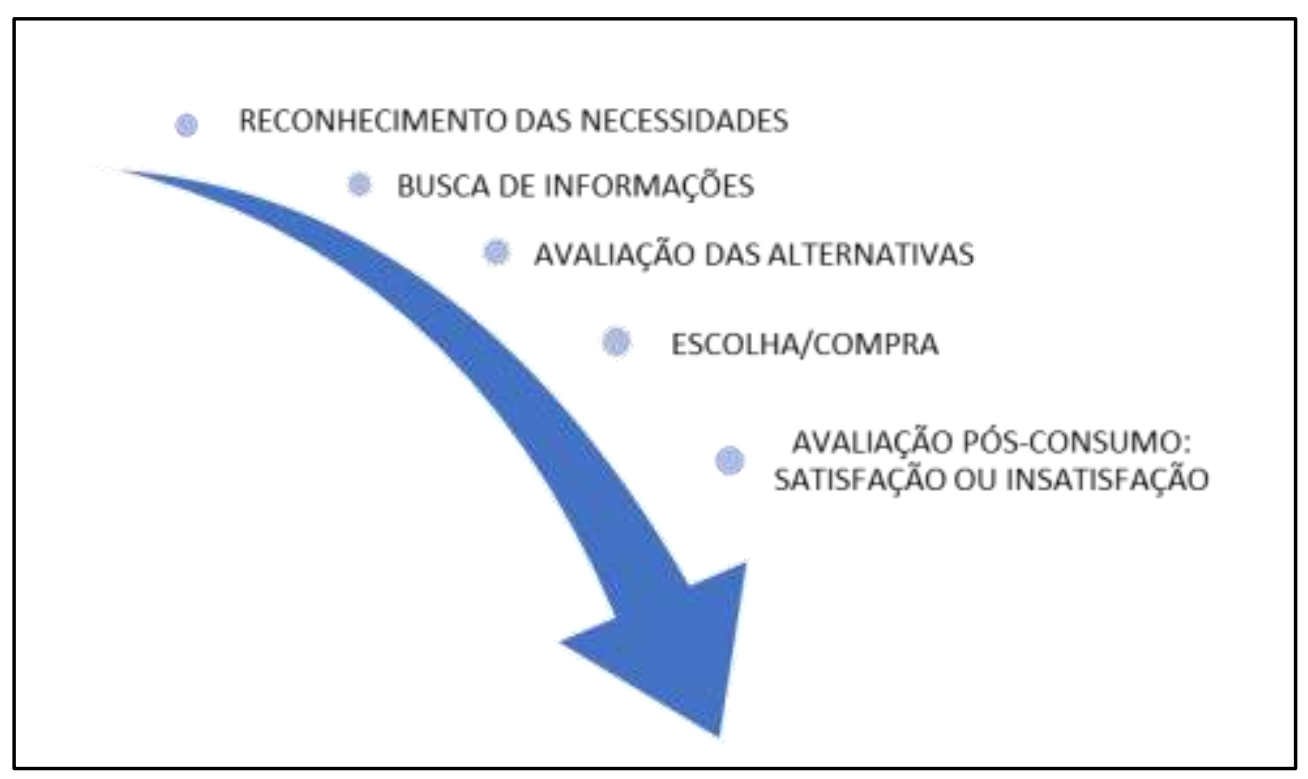

Fonte: Autores (2021).

O consumidor age de forma racional, com o objetivo de fomentar a satisfação, assim para suprir suas necessidades busca, um produto que possua utilidade, com possibilidade de substituição (Rossetti, 2003). O reconhecimento das necessidades é o ponto de partida do consumidor, onde o mesmo reconhece que tem necessidade de utilizar um bem ou serviço (Barbosa, 2015).

Logo depois, o consumidor busca informação, e essa busca comumente ocorre por meio dos familiares, amigos e em sites de pesquisa na WEB. Para saber se é vantajoso ou não comprar determinado produto ou consumir um serviço. Assim quanto mais informação um consumidor tiver sobre um produto ou serviço, maiores serão suas atitudes positivas ou negativas em relação ao mesmo. (Schiffman \& Kanuk, 2000).

Outra estratégia que o consumidor tem é o sentido de cognição, onde se tem armazenado a informação, da lembrança de sua experiência passada que se teve com o produto, desta forma os consumidores definem se o produto é bom ou ruim. Depois disso acontece a avaliação das alternativas, onde os consumidores ponderam sobre as que se têm disponíveis, buscando sempre respostas que vão satisfazer as necessidades a serem atendidas (Solomon, 2002). 
E finalmente ocorre a efetivação da compra, neste momento o mesmo manifesta a opção por um determinado produto, ou marca. Isto ocorre conforme a natureza do produto. Todavia o envolvimento é medido por meio da natureza do produto, por exemplo, o envolvimento de quem compra um carro é diferente daquele que compra alimentos, pois um carro não se compra com tanta frequência se comparado a produtos alimentícios (Garcia et al., 2008). O autor ainda ressalta, que após a escolha do produto, o consumidor irá utilizá-lo conforme a utilidade do mesmo. Esta utilização pode ocorrer de imediato ou em um momento posterior, dependendo da necessidade.

Depois de todas essas etapas acontece a avaliação pós-consumo, onde se diz respeito à opinião do consumidor, se o produto atendeu ou não a sua necessidade de consumo. Quando se tem uma experiência que não correspondeu às suas expectativas, o comprador fatalmente ficará insatisfeito. Para que aconteça a satisfação é necessário seguir alguns critérios, de acordo com (Rodrigues \& Costa, 2018), a satisfação por parte do consumidor, inicia-se ao realizar a compra e enfim, faz-se o uso do produto, por sua parte este, faz a comparação entre os benefícios oferecidos e as expectativas referente ao mesmo. Somente após o consumo, saberá se o produto satisfez ou não sua necessidade de consumo.

\section{Conclusão}

O comportamento do consumidor compõe-se particularmente por intermédio dos fatores como, psicológicos, sociais, culturais e estruturais do indivíduo, porem aquilo que irá influenciá-lo a tomada de decisão ou no desejo de consumir um produto ou serviço, pode variar muito. Ou seja, não se tem uma única forma de pensamento a qual se define como o consumidor comportase perante suas decisões de compra, não se pode ter uma conclusão para generalizar tal, ou seja, não há uma receita pronta nesse sentido.

Por intermédio desse estudo procurou-se identificar as incógnitas contidas no comportamento do consumidor no momento de comprar. Sendo assim, na síntese observacional do registro dos fatores motivacionais - psicológicos, pessoais, sociais, culturais e grupos de referência - verificamos que as questões determinantes nesses aspectos são de ordem intrínsecas e de influências externas. Quanto as fontes condicionantes as atitudes - emoção, benefícios, status, utilidade e cognição observamos que as tais, encontram-se no campo da fisiologia humana, ou seja, na busca pela satisfação. Atinente as fases que compõem o processo decisório do consumidor - busca de informação, avaliação de alternativas, escolha (compra), e análise póscompra - constatamos que nesta etapa ocorre a busca pela a realização das necessidades do consumidor.

Portanto entender a necessidade e os anseios do consumidor não é tarefa fácil, pois além dos fatores de ordem comportamental supracitados, há outros pontos abrangentes como financeiro e localidade, que não foram objetos deste estudo, mas que igualmente devem ser considerados. O que desperta a atenção para a exigência de profissionais habilitados para o atendimento deste público, onde não somente o colaborador, mas também a empresa precisa estar em sintonia com cada detalhe novo que porventura venha ser inserido neste contexto.

E fica aqui a sugestão para que outros pesquisadores possam acrescentar seus estimáveis entendimentos a uma questão primorosa, que o avanço do e-commerce e as nuances contidas nos elementos que influenciam no âmbito comportamental do consumidor virtual. Porque neste meio, só o que há de perene é a mudança constante.

\section{Referências}

Ambros, L. (2019). Processo de decisão de compra. https://administradores.com.br/artigos/processo-de-decisao-de-compra.

Barbosa, T. D., Trigo, A. C., \& Santana, L. C. D. (2015). Qualidade no atendimento como fator de crescimento empresarial. Revista de Iniciação CientíficaRIC Cairu, 2(02), 112-133.

Binotto, S., Denardin, É. S., Medeiros, F. S. B., Boligon, J. A. R., \& Machado, F. F. (2014). Os fatores de influência no comportamento do consumidor: um estudo em uma cooperativa agrícola do RS. Revista de Gestão e Organizações Cooperativas, 1(2), 13-26. 
Casarin, S. T., Porto, A. R., Gabatz, R. I. B., Bonow, C. A., Ribeiro, J. P., \& Mota, M. S. (2020). Tipos de revisão de literatura: considerações das editoras do Journal of Nursing and Health/Types of literature review: considerations of the editors of the Journal of Nursing and Health. Journal of Nursing and Health, 10(5).

Castilhos, R. B. (2007). Subindo o morro: consumo, posição social e distinção entre famílias de classes populares. https://www.lume.ufrgs.br/handle/10183/8933

Cavazza, N. (2008). Psicologia das atitudes e das opiniões. Edições Loyola.

Chrestenzen, R., \& dos Santos, S. E. (2018). Fatores determinantes nas decisões de consumo das famílias no município de Curitiba. Caderno PAIC, 19(1), 219242 .

Content, R. (2017). Consumismo no Brasil: entenda o que é realmente é conheça o panorama no país. https://rockcontent.com/blog/consumismo-no-brasil/>

Fernandes, C. (2010). O capitalismo e o advento de uma sociedade de consumo. Colégio Mãe de Deus, 1(1).

Franco, R., Leite, M., Bonini, M., Brandão, C., \& Sant'ana, A. (2017). Um recorte sobre psicologia social e psicologia do consumidor. Revista FAIPE, 6(2), 7385 .

Garcia, M. N., da Silva, D., da Silva Pereira, R., Rossi, G. B., \& Minciotti, S. A. (2008). Inovação no comportamento do consumidor: recompensa às empresas socioambientalmente responsáveis. RAI-Revista de Administração e Inovação, 5(2), 73-91.

Gil, A. C. (2002). Como elaborar projetos de pesquisa (Vol. 4, p. 175). Atlas.

Gomes, E. G. S., Domingues, D. A. S. D., \& Biazon, V.V. (2020). Comportamento do consumidor: fatores que influenciam o poder de compra. Scientific Electronic Archives, 14(4). https://doi.org/10.36560/14420211252.

Kotler, P. (2000). Administração de marketing.

Kotler, P. (2006). KELLER, Kevin Lane. Administração de marketing, 12.

Kotler, P., \& Armstrong, G. (2007). Princípios de marketing. Pearson Prentice Hall.

Las Casas, A. L. (2000). Marketing: conceitos, exercícios, casos. Editora Atlas SA.

Limeira, T. M. V. (2008). Comportamento do consumidor brasileiro. Saraiva Educação SA.

Marques, C. L., \& Pfeiffer, R. C., (2020). Superendividamento dos consumidores: Vacina é o PL 3.515 de 2015.

Mota, H. (2021). Estratégias de marketing garantem o sucesso do produto no mercado. https://www.sebrae.com.br/sites/PortalSebrae/artig os/artigoshome/estrategias-de-marketing-garantem-o-sucesso-do-produto-no-mercado,b10032736a186410VgnVCM1000003b74010aRCRD.

Moura, R. G. (2019). Esculpindo Barbies por meio de suplementos alimentares: corpo, gênero e consumo por uma ótica Queer. Diálogo com a Economia Criativa, 4(10), 60-77.

Oliveira, M. F. (2011). Metodologia científica: um manual para a realização de pesquisas em Administração. Universidade Federal de Goiás. Catalão-GO.

Ribeiro, E. (2010). Classe média busca produtos mais práticos e sofisticados, aponta Nielsen. https://www.infomoney.com.br/mercados/classe-media-buscaprodutos-mais-praticos-e-sofisticados-aponta-nielsen/

Richardson, R. J. (2017). Pós-Graduação-Metodologia-Pesquisa Social: Métodos e Técnicas-Métodos Quantitativos e Qualitativos-Capitulo 5.

Rodrigues, A. S.; \& costa, O. A. C. (2018). Atendimento aos clientes como vantagem competitiva. 2018, monografia. (Curso de administração). Centro Universitário Fimca, Porto Velho. (2018).

Rossetti Solomon, J. P. (2003). Introdução à economia. (20a edi.). Atlas.

Sachs Larrain J.D. \& Larrain B. F. (2000). Macroeconomia: Em uma economia Global. Pearson Education do Brasil.

Sauerbronn, J. F. R., Ayrosa, E. A. T., \& Barros, D. F. (2009). Bases sociais das emoções do consumidor: uma abordagem complementar sobre emoções e consumo. Cadernos EBAPE. BR, 7, 169-182.

Schiffman, L.G.; Kanuk, L. (2000). Comportamento do consumidor. (6a ed.), LTC.

Selltiz, C., \& Deutch, C. (1965). Métodos de Pesquisa nas relações sociais. [trad.]. Inah de Oliveira Ribeiro, Ed. Herder, 223-310.

Silva, M. E., Aguiar, E. C., Falcão, M. C., \& Costa, A. C. V. (2012). A perspectiva responsável do Marketing e o Consumo Consciente: Uma interação necessária entre a empresa e o consumidor. Revista Organizações em Contexto, 8 (16), 61-90.

Silva,G. , E. G., Domingues, D. A. D. S. D., \& Biazon, V. V. (2021). Comportamento do consumidor: fatores que influenciam o poder de compra. Scientific Electronic Archives, 14(4).

Solomon, M. R. (2002). O comportamento do consumidor: comprando, possuindo e sendo. (5a ed.), Bookman.

Sousa, R. (2021) "Primeira Revolução Industrial"; Brasil Escola. https://brasilescola.uol.com.br/geografia/primeira-revolucao-industrial.htm.

Teixeira, J.C.I. (2010). Fatores que influenciam o comportamento do consumidor. http://www.avm.edu.br/docpdf/monografias_publicadas/k212800.pdf 
Research, Society and Development, v. 10, n. 14, e580101422390, 2021

(CC BY 4.0) | ISSN 2525-3409 | DOI: http://dx.doi.org/10.33448/rsd-v10i14.22390

Tylor, E. B. (2014). A ciência da cultura. Editora Schwarcz-Companhia das Letras.

Ugalde, M., \& Slongo, L. A. (2006). As emoções e o processo decisório de compra de imóveis por consumidores da terceira idade. XXX EnANPAD-Encontro Nacional dos Programas de Pós-Graduação em Administração. 